\title{
O GÊNERo Hebanthe (AMARANTHACEAE) NO BraSIL ${ }^{1}$
}

\author{
Maria Salete Marchioretto ${ }^{2}$, Silvia Teresinha Sfoggia Miotto ${ }^{3}$ \\ \& Josafá Carlos de Siqueira ${ }^{4}$
}

\begin{abstract}
Resumo
(O gênero Hebanthe (Amaranthaceae) no Brasil) Este estudo apresenta uma revisão taxonômica do gênero Hebanthe Mart. (Amaranthaceae) no Brasil. Seis espécies são confirmadas para o Brasil: Hebanthe eriantha (Poir.) Pedersen, H. grandiflora (Hook.) Borsch \& Pedersen, H. occidentalis (R.E.Fr.) Borsch \& Pedersen, $H$. pulverulenta Mart., H. reticulata (Seub.) Borsch \& Pedersen e H. spicata Mart. São feitas sinonimizações de variedades e formas. As espécies de Hebanthe são encontradas em formações florestais, principalmente no interior e em bordas de matas ciliares, semi-decíduas e pluvial-atlântica. Além da chave para identificação das espécies são apresentadas descrições, ilustrações, informações sobre o hábitat e distribuição geográfica, comentários taxonômicos e nomenclaturais.
\end{abstract}

Palavras-chave: taxonomia, formações florestais, Hebanthe, Amaranthaceae.

\section{Abstract}

(The genus Hebanthe (Amaranthaceae) in Brazil) This study presents a revision of the genus Hebanthe Mart. (Amaranthaceae) in Brazil. Six species are confirmed for Brazil: Hebanthe eriantha (Poir.) Pedersen, $H$. grandiflora (Hook.) Borsch \& Pedersen, H. occidentalis (R.E.Fr.) Borsch \& Pedersen, H. pulverulenta Mart., H. reticulata (Seub.) Borsch \& Pedersen e H. spicata Mart. Synonimizations of varieties and forms are presented. The species occur in forest formation, mainly in edges and interiors of riparian, semi-deciduous, and pluvial atlantic forests. Descriptions, identification keys, nomenclatural comments, ilustrations of the diagnostic caracteres are presented together with information on species habtitats, geographical distributions. Key words: taxonomy, forest formation, Hebanthe, Amaranthaceae.

\section{INTRODUÇÃOO}

A família Amaranthaceae Juss. é considerada tropical e subtropical. De acordo com as características morfológicas e moleculares pertence à ordem Caryophyllales e engloba as Chenopodiaceae (Judd et al. 2002; APG II 2003), incluindo cerca de 170 gêneros e 2000 espécies, sendo que no Brasil ocorrem 20 gêneros nativos e aproximadamente 100 espécies (Marchioretto et al. 2008). O gênero Hebanthe apresenta quatro espécies de acordo com Martius (1826) e Dietrich (1839). Outros autores como Endlicher (1837) e Moquin-Tandon (1849) consideram o gênero como uma secção de Gomphrena L., também com quatro espécies. Já Kuntze (1891), Fries (1920), Sussenguth (1934) e Stützer (1935) aceitam a secção Hebanthe como pertencente ao gênero Pfaffia Mart., com respectivamente seis, sete, 11 e 10 espécies. Para Borsch \& Pedersen (1997), que restauraram a categoria genérica deste grupo, o gênero compreende sete espécies.

As espécies de Hebanthe são encontradas em formações florestais, principalmente no interior e em bordas de matas ciliares, semidecíduas e pluvial-atlântica. Caracterizam-se pelo hábito arbustivo, subarbustivo, semiescandente ou escandente, folhas opostas, inflorescências em espigas reunidas em panículas, flores bissexuais e frutos cápsulas monospérmicas.

A distribuição geográfica de Hebanthe não é bem conhecida, entretanto Borsch \& Pedersen (1997) argumentam que as espécies ocorrem

Artigo recebido em 04/2009. Aceito para publicação em 11/2009.

${ }^{1}$ Parte da tese de Doutorado da primeira autora, contato: saletemarchioretto@gmail.com; herbariopaca@unisinos.br.

${ }^{2}$ Instituto Anchietano de Pesquisas, Herbarium Anchieta, R. Brasil 725, CP 275, 93001-970, São Leopoldo, RS.

${ }^{3}$ Universidade Federal do Rio Grande do Sul, Depto. Botânica, Av. Bento Gonçalves 9500, Bloco IV, prédio 43433, 91501-970, Porto Alegre, RS. Bolsista de Produtividade do CNPq.

${ }^{4}$ PUC-Rio, Depto. Geografia e Meio Ambiente da PUC-Rio, R. Marquês de São Vicente 398, 22451-041, Rio de Janeiro, RJ. 
desde o México à América Central continental ao longo de encostas e colinas dos Andes até a região de Yungas na Bolívia e nordeste argentino, alcançando as terras baixas do leste da Bolívia e Paraguai, atingindo o sul do Brasil, estando aparentemente, ausente no Caribe.

Para o Brasil não existe nenhuma revisão para o gênero. No entanto, trabalhos taxonômicos com espécies do gênero foram realizados por Suessenguth (1934), Stützer (1935) Vasconcellos (1986), Borsch \& Pedersen (1997) e Pedersen (2000). Estes estudos, porém, apresentam limitações em alguns aspectos, tais como: falta de informações sobre distribuição geográfica, morfologia e posição taxonômica das espécies, além de considerações filogenéticas.

O objetivo do presente trabalho é o estudo taxonômico das espécies brasileiras de Hebanthe.

\section{Material e Métodos}

O estudo foi baseado no exame de aproximadamente 490 exsicatas, pertencentes ao acervo de 43 herbários nacionais e internacionais, relacionados a seguir pelas siglas, de acordo com (Thiers 2009, continuamente atualizado): ALCB, $\mathrm{B}, \mathrm{BHCB}, \mathrm{BHZB}, \mathrm{C}, \mathrm{CEN}, \mathrm{CEPEC}, \mathrm{CESJ}, \mathrm{CH}$, CPAP, CTES, ECA, ESA, FCAB, GUA, HAS, HB, HBR, HRB, HRCB, HTO, HUEFS, IAC, IAN, IBGE, ICN, JPB, K, MBM, MG, NY, P, PACA, R, RB, S, SI, SJRP, SP, SPF, UB, VEN, VIC. Além disso, foram examinados tipos nomenclaturais e/ou fotografias procedentes dos herbários $\mathrm{C}, \mathrm{K}, \mathrm{NY}, \mathrm{P}, \mathrm{R}$ e S. Também foram realizadas observações e expedições no campo para coleta de material in situ em Mato Grosso, Minas Gerais, Paraná, Rio Grande do Sul e Santa Catarina. A coleção-testemunho foi depositada nos herbários PACA e ICN.

As sinonímias das espécies se encontram em Borsch \& Pedersen (1997) e Pedersen (2000). No presente trabalho são citados apenas os basiônimos e as sinonimizações novas. Para as descrições das espécies seguiu-se o procedimento usual em taxonomia, por meio da análise morfológica, complementada com os dados de etiquetas das exsicatas e coletas em campo. A terminologia utilizada nas descrições foi baseada em Hickey (1974) e Radford et al. (1974), além de Payne (1978) para indumento e tricomas. As citações das obras seguiu-se o Botanico-Periodicum- Huntianum (Lawrence et al. 1968) e Taxonomic Literature (Stafleu \& Cowan 1976-1988), e as abreviações dos nomes de autores conforme Brummitt \& Powell (1992). As ilustrações do hábito das espécies foram feitas a partir de fotocópias das exsicatas, desenhadas à nanquim sobre papel vegetal. As demais ilustrações foram feitas com auxílio câmara-clara e microscópios estereoscópicos Carl Zeiss e Olympus utilizando-se material herborizado hidratado.

Os ambientes em que ocorrem as espécies foram determinados a partir das fichas de coletas, observações em campo e bibliografia especializada, destacando-se, Cabrera \& Willink (1980), Andrade-Lima (1981), Rizzini et al. (1988), Eiten (1990) e Fernandes (1998).

\section{Resultados e Discussão}

\section{Tratamento taxonômico}

Hebanthe Mart., Beitr. Amarantac. 96. 1825. Subarbustos, arbustos, escandentes a semiescandentes, ramosos, glabros, pilosos ou velutinos; sistema subterrâneo gemífero, fusiforme, lenhoso. Folhas opostas, ovadas, ovado-elípticas, ovadolanceoladas, elípticas a elíptico-lanceoladas, pecioladas; ápice agudo a acuminado, base aguda, arrendondada, cuneada a obtusa, glabras, estrigosas, híspidas, pilosas ou velutinas, tricomas adpressos, articulados ou estrelados, membranáceas a cartáceas. Inflorescências em espigas, reunidas em panículas, ramificação tricotômica ou multicotômica, axilares ou terminais, pedúnculo curto ou longo glabro, estrigoso, piloso a velutino, tricomas estrelados, pulverulentos; três brácteas hialinas, escariosas, desiguais, duas laterais e uma mediana, glabras a pilosas. Flores bissexuais, cinco sépalas livres, três externas e duas internas, pilosas, ovadas, ovado-oblongas, lanceoladas, elípticas, elíptico-ovadas a ovado-lanceoladas, tubo estaminal curto, com ou sem filamentos laterais, quando existentes curtos, quase do mesmo tamanho ou ultrapassando o anterífero, anteras elípticas ou oblongas, ovário bicarpelar, oblongo, 
obovado, ovado, subesférico, globoso, um rudimento seminal; estilete curto ou ausente; estigma capitado, capitado-bilobado ou capitado- emarginado. Fruto cápsula monospérmica, inclusa nas sépalas, semente lenticular.

Espécie-tipo: Hebanthe paniculata Mart.

\section{Chave para identificação das espécies de Hebanthe Mart.}

1. Folhas e ramos com tricomas estrelados.

2. Tubo estaminal sem filamentos laterais

H. occidentalis

2'. Tubo estaminal com filamentos laterais

H. pulverulenta

1.' Folhas e ramos sem tricomas estrelados.

3. Bráctea mediana ovado-côncava

H. eriantha

3'. Bráctea mediana orbicular, suborbicular ou subglobosa.

4. Folhas com nervuras secundárias reticuladas

H. reticulata

4'. Folhas com nervuras secundárias não reticuladas.

5. Tubo estaminal com filamentos laterais maiores ou do mesmo tamanho do filamento anterífero H. spicata

5'. Tubo estaminal sem filamentos laterais H. grandiflora

1. Hebanthe eriantha (Poir.) Pedersen, Bonplandia 19(1-4): 101.2000. Fig. 1 a-g

Iresine erianthos Poir., Encycl. Suppl. 3: 180. 1813. Tipo: BRASIL, P. Commerson $s / n$. (lectótipo P- fotografia !, designado por T. M. Pedersen (2000)).

Hebanthe eriantha f. ovatifolia (Heimerl) Pedersen. Bonplandia 19(1-4): 102.2000. Syn. nov. Tipo: BRASIL . SÃO PAULO: prope $\mathrm{S}$. Bernardo in circuitu urbis, Waschsmund $s / n$ (W perdido); BRASIL. $A$. F. M. Glaziou 11433 (neótipo C!, designado por T. M. Pedersen (2000)).

Subarbusto ou arbusto, semi-escandente a escandente, 0,90-1,80 $\mathrm{m}$ de altura, caule lenhoso na base, ascendente, engrossado nos nós, glabro a esparsamente estrigoso, híspido ou piloso, principalmente nos ramos jovens; folhas ovadas, ovado-elípticas, ovadolanceoladas, elíptico-lanceoladas, $2-15 \times 0,8$ $5,8 \mathrm{~cm}$, pecíolos estrigosos a pilosos, tricomas articulados, 0,3-1,5 cm compr., ápice agudo a acuminado, base aguda a arredondada; face adaxial glabra a levemente estrigosa ou pilosa, principalmente nas nervuras, tricomas articulados ou segmentados, face abaxial subglabra a levemente estrigosa ou pilosa, tricomas articulados; inflorescência espiga, em panícula, multicotômica, axilar ou terminal, flores pequenas, esbranquiçadas,
2-3,5 mm compr., pedúnculo estrigoso a piloso, castanho a ferrugíneo; bráctea mediana ovada, côncava, uninervada, pilosa na base e nos lados laterais, 1-1,7 mm compr., brácteas laterais suborbiculares, côncavas, pilosas no dorso, 1$1,5 \mathrm{~mm}$ compr.; três sépalas externas ovadas, ápice agudo, trinervadas, pilosas a subglabras, castanho-escuras, 2-3 mm compr., grande quantidade de tricomas longos entre as sépalas externas e internas, quase ultrapassando o comprimento das sépalas externas, duas sépalas internas ovadas, trinervadas, pilosas, castanhoclaras, 1,5-2 mm compr.; tubo estaminal curto, filamentos laterais subtriangulares, mais curtos ou às vezes quase do mesmo tamanho do filamento central anterífero, linear; anteras oblongas, 0,5-0,8 mm compr.; ovário ovado ou globoso, 0,8-1,5 mm compr., estigma capitadobilobado ou capitado-emarginado.

Material examinado selecionado: BAHIA: Andaraí, $45 \mathrm{~km}$ N de Andaraí, 9.X.1987, fl. e fr., L.P. Queiroz et al. 1788 (ALCB, VIC). Bom Jesus da Lapa, Rodovia Igopora-Caetite km 8, 2.VII.1983, fl. e fr., $L$. Coradin et al. 6362 (CTES, HRCB). Encruzilhada, entre Encruzilhada e Ribeirão do Largo 15.VIII.2001, fl., A.M. Carvalho et al. 6926 (ALCB). Jussari, Rod. Jussari/Palmira, 13.VIII.1998, fl. e fr., A.M. Amorim et al. 2451 (CEPEC). Poções, entre Poções e Bom Jesus da Serra, 5.III.1978, fl., S.A. Mori et al. 9483 (CEPEC, NY). DISTRITO FEDERAL: Brasília, Bacia do Rio 
São Bartolomeu, 13.VIII.1980, fl. e fr., E.P. Heringer et al. 5308 (MG). ESPÍRITO SANTO: Colatina, Vale de Pancas, 8.IX.1977, fl. e fr., J.D. Shepherd et al. 5873 (MBM, MG, R). MATO GROSSO: Cáceres, Reserva do Taiamã, VIII.1980, fl., L. Rossi et al. s/n (MBM, PACA, SPF 16734). MATO GROSSO DO SUL: Ponta Porã, entre Ponta Porã e Amambaí, 19.VII.1977, fl. e fr., P.E. Gibbs et al. 5322 (MBM). MINAS GERAIS: Conceição do Mato Dentro, Parque Municipal do Ribeirão do Campo, 8.VIII.2003, fl. e fr., J. Mota 2159 (BHCB); Espera Feliz, 8.VIII.1983, fl. e fr., G. Hatschbach 46809 (CTES, BHCB, MBM); Iragurara, 13.X.1981, fl. e fr., G. Hatschbach 44226 (CTES). Marliéria, Parque Estadual do Rio Doce, 26.V.2001, fl., J.R. Stehmann et al. 2954 (BHCB). Ponta Queimada, 29.VIII.1973, fl. e fr., B.D. Sucre et al. 10128 (SP). Rio Vermelho, 20.VIII.2003, fl. e fr., V.C. Souza 361 (HRCB). Vale Verde, Parque Nacional da Serra do Caparaó, Córrego do Inácio, 17.XII.1988, fl., L. Krieger et al. 23335 (HRCB). PARANÁ: Campo Largo, Serra São Luís, 18.I.1968, fl. e fr., G. Hatschbach 18291 (CTES, MBM). Mandirituba, Quatro Pinheiros, 28.VIII.1962, fl. e fr., G. Hatschbach 9239 (MBM). Piraquara, Florestal p. Piraquara, 31.VII.1949, fl. e fr., G. Hatschbach 1435 (MBM, PACA). Tibagi, Fazenda Monte Alegre, Antas, 4.VIII.1960, fl., G. Hatschbach et al. 7267 (MBM). RIODE JANEIRO: Barra do Piraí, perto do Rio Paraíba do Sul, 23.VII.1986, fl. e fr., J.P.P. Carauta 5337 (GUA, R). Cabo Frio, Búzios, Praia José Gonçalves, 26.VII.1991, F.S. Araújo et al. 9448 (GUA). Itaguaí, Estrada do Caçador, 3.IX.1990, fl., J.P.P. Carauta et al. 6149 (GUA). Niterói, Itaipú, Morro das Andorinhas, 6.VIII.1980, fl., F.S. Araújo et al. 3912 (GUA, NY). Paraíba do Sul, entre Queima Sangue e Salustris, 24.VII.1984, fl. e fr., J.P.P. Carauta et al.4765(GUA). RIOGRANDEDOSUL: CerroLargo, p. São Luiz, 3.X.1946, fl. e fr., Irm. Augusto 041 (PACA). Derrubadas, Parque Estadual do Turvo, 30.VII.1985, fl. e fr., N. Silveira et al. 2840 (HAS); Marcelino Ramos, na barranca do Rio Uruguai, 23.IX.1987, fl. e fr., J.A. Jarenkow, 729 (ICN, PACA). Porto Mauá, 30 VIII.1970, fl., K. Hagelund 5922 (CTES). RORAIMA: Canta Galo, Rio Mucajaí, between Pratinha and Rio Apiaú, 22.I.1967, fl. e fr., GT. Prance et al. 3976(MG). SANTACATARINA: Itapiranga, 29.VIII.1964, fl. e fr., R. Klein 5639(HBR, NY,PACA). Mondaí, 28.VIII.1964, fl. e fr., R. Klein 5634 (HBR). Pirituba, Uruguai, 11.VII.1963, fl., R. Reitz \& R. Klein 15377 (HBR). São Miguel do Oeste, 24.IX.2006, fl. e fr., M.S. Marchioretto 298 (PACA). SÃO PAULO: Analândia, 22.VIII.1995, fl. e fr., P. Morellato et al. 1008 (ESA,HRCB). Campinas, Fazenda São Vicente, 23.VIII.1989, fl., L.C. Bernacci, $s / n$ (ESA 14493). Gália, Estação Ecológica de Olavo Amaral Ferraz, 7.VII.1994, fl. e fr., J.R. Pirani et al. 3277 (ESA, HRCB, PACA, SPF). Iperó, Flona Ipanema, 6.VIII.1994, fl. e fr., M.C. Mamede et al. 574 (HRCB). Marabá Paulista, Rodovia SP 563, 26.VII.1997, fl. e fr., M.R. Pietrobom Silva 4119 (SJRP). Rio Claro, 23.VII.2002, fl. e fr., D.G. Picchi \& M.A. Assis 150 (HRCB,PACA). Sales, Fazenda ÁguaClara, 24.VIII.1995, fl. e fr., M.D.N.Grecco et al. 131 (HRCB, SJRP, SPF). Tietê, 10.VIII.1987, fl., A. Loefgren 11052 (NY).

Material adicional selecionado: ARGENTINA. MISIONES: Cainguás, Ruta $145 \mathrm{~km}$ E de Aristóbulo del Valle, 29.VII.1987, fl. e fr., R. O. Vanni et al. 824 (CTES). Guaraní, Predio Guaraní, 24.VIII.1996, fl. e fr., S.G. Tressens et al. 5667 (CTES). Iguazú, Puerto Bosetti, 18.VIII.2003, fl. e fr., H.A. Keller et al 2311 (CTES). PARAGUAI. Alto Paraná, Reserva Biológica Tatí, Yupí, 14.VII.1979, fl. e fr., Marmoni 422 (CTES). Caaguazú, 16.IX.1988, fl. e fr., T.M. Pedersen 15032 (CTES). Rumbo Norte, 20.VIII.1996, fl. e fr., B. Jiménez 1406 (CTES). PERU. San Martin, Lamas, 1.X.1937, fl. e fr., Belshaw 3495 (SI)

Hebanthe eriantha passou por uma série de alterações nomenclaturais, as quais foram apresentadas por Pedersen (2000), com uma lista de sinônimos, onde o autor tece inúmeros comentários justificando a sinonimização de cada epíteto.

Neste trabalho propõe-se a sinonimização de Hebanthe eriantha f. ovatifolia (Heimerl) Pedersen, em favor de Hebanthe eriantha (Poir.) Pedersen. Após o exame do neótipo da forma ovatifolia, além da análise de um considerável número de espécimens, constatou-se que, quando foi proposta a forma ovatifolia para Gomphrena paniculata por Heirmel (1908), o autor separava-a pela forma do limbo foliar ovado-eliptíco e base arredondada, aguda. No entanto, a ampla distribuição geográfica da espécie observada em todas as regiões do Brasil, em diferentes ecossistemas, sofrendo diversas variações edáficas e climáticas, permite inferir que a diversificação de ambientes muitas vezes condiciona o número, tamanho e forma de algumas estruturas vegetativas e reprodutivas. Neste caso, possivelmente, acarretou no aumento de tamanho e modificações na forma do limbo foliar, não justificando manter-se como uma forma distinta. 


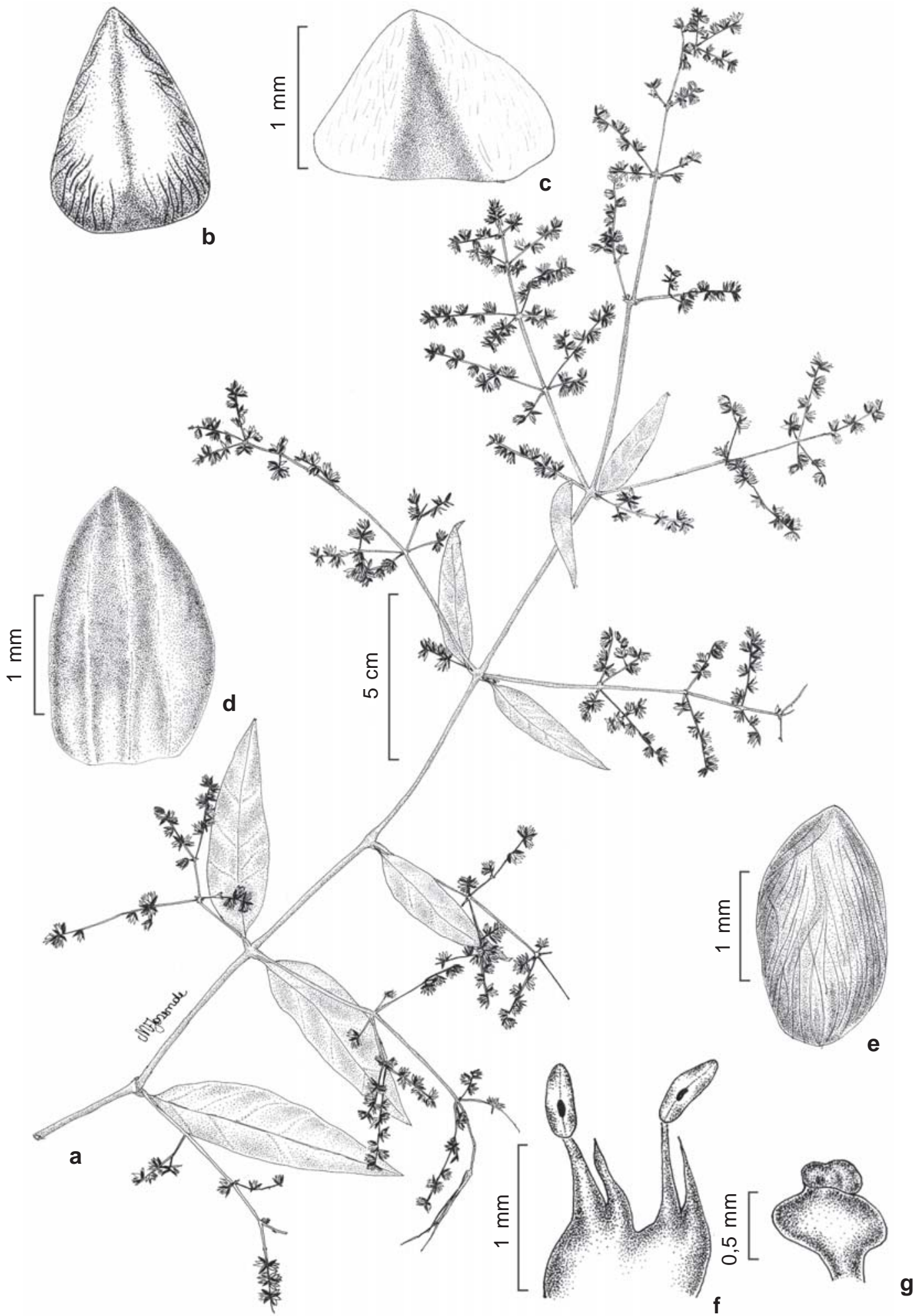

Figura 1 - Hebanthe eriantha (Poir.) Pedersen - a. ramo; b. bráctea mediana; c. bráctea lateral; d. sépala externa; e. sépala interna; f. tubo estaminal; g. ovário. (Rambouts 119, IAC).

Figure 1 - Hebanthe eriantha (Poir.) Pedersen - a.branch; b. median bract; c. lateral bract; d. outer sepal; e. inner sepal; f. staminal tube; g. ovary. (Rambouts 119, IAC). 
2. Hebanthe grandiflora (Hook.) Borsch \& Pedersen, Sendtnera 4. 20. 1997.

Fig. 2 a-g

Iresine grandiflora Hook., Icon. Pl. 2: 102. 1837. Tipo: PERU. Cordilheira of Casapi, $H$. J. Mathews 1419 (holótipo K- fotografia !).

Arbusto escandente, caule cilíndrico, ramos castanho-claros, estriados, glabros a brevemente pilosos, tricomas dispersos, adpressos; folhas elípticas a ovadas, 4-9 × 1,5-4 cm, pecíolos brevemente pilosos, tricomas adpressos $0,5-1 \mathrm{~cm}$ compr., ápice acuminado, base cuneada, face adaxial glabra, face abaxial estrigosa a pilosa nas nervuras; inflorescência espiga, em panícula, multicotômica, axilar ou terminal, flores castanho-claras 2-3 mm compr., pedúnculo estrigoso a piloso, bráctea mediana orbicular, ápice agudo, densamente pilosa no dorso, 0,8-1 mm compr., brácteas laterais orbiculares, côncavas, hialinas, ápice agudo, 1-1,5 mm compr., entre as brácteas e sépalas, tricomas alvos, quase do mesmo tamanho das sépalas; três sépalas externas ovadas, ápice agudo a obtuso, trinervadas, pilosas, castanho-claras, base castanho-escura, 1,5-2 mm compr., duas sépalas internas ovadas, ápice agudo a obtuso, trinervadas, pilosas, base castanho-escura, 11,5 mm compr.; tubo estaminal sem filamentos laterais ou formando uma breve elevação, filamento anterífero filiforme, anteras oblongas, 0,7-1 mm compr.; ovário subesférico a elíptico, $1,5 \mathrm{~mm}$ compr., estigma capitado.

Material examinado selecionado: ESPÍRITO SANTO: Linhares, Reserva Florestal de Linhares, 31.VIII.1993, fl. e fr., D.A. Folli 1975 (HRCB). MATO GROSSO: Sararé, 9.VIII.1978, fl. e fr., J.M. Pires \& M.R. Santos 16496 (MG, NY). MATO GROSSO DO SUL: Brasilândia, Rio Paraná, Fazenda Santa Maria, 23.VII.1996, fl. e fr., M.A. Pietrobom Silva 3486 (SJRP). Material selecionado adicional: BOLÍVIA. LAPAZ: Sud yungas, Chulumani, 52 km haciaAsunta, 8.VIII.1983, S.G. Beck 8591 (CTES). SANTA CRUZ: Nuflo de Chavez Reserva de Vida Silvestre Rios Blanco Y Negro, 11.VII.1992, fl. e fr., M. Saldias et al. 1776 (CTES). TARIJA: Arce, Bermejo, 19.X.1983, fl. e fr., S.G. Beck 9591 (SI). EQUADOR. NAPO: Carretera Hollin-Loreto-Coca, 8.XII.1987, fl. e fr., B. Zak et al. 3116(CTES). PERÚ. HUANUCO: Pachitea, Pucallpa, 12.VIII.1988, fl. e fr., G.K.Gottsberger \& H. Döring 116-12888(CTES); Chirechavilla, 14.IX.1949, fl., J.
Scolnik; s/n (SI). VENEZUELA. MIRANDA: Cerros del Bachiller, above Quebrada Corozal, south of Santa Cruz, 20.III.1978, fl. e fr., J.A. Steyermark \& G. Davidse $s / n$ (VEN 135435).ZULIA: Serra de Perijá, cerca de la frontera Colombo-Venezolana, 22.III.1972, fl. e fr., J.A. Steyermark \& G.C.K. Dunsterville s/n (VEN 92242). Distribuição geográfica e hábitat: no Brasil somente nos estados de Espírito Santo, Mato Grosso e Mato Grosso do Sul, na transição entre cerradão e mata. Ocorre também no Equador, Bolívia, Peru e Venezuela.

Fries (1920) considerou a espécie pertencente ao gênero Pfaffia e argumentou que a identificação deste táxon foi feita a partir de uma pequena descriçãoe ilustração, em Hooker (1837) de Iresine grandiflora. Fries $(l$. $c$.) ainda comentou que a espécie se expande da América Central para o sul ao longo dos Andes até o norte da Argentina e em parte para o leste, em direção ao Mato Grosso e que cresce em borda de mata, com 10 a 12 m de altura, com hábito escandente.

Eliasson (1987) também a considerou como uma espécie de Pfaffia, ressaltando que $P$. grandiflora difere de $P$. paniculata na morfologia das inflorescências e pela ausência de filamentos entre os estames. Eliasson (l. c.) ainda comentou que a distribuição da espécie vai do México para o norte do Peru e sul da Bolívia e que, geralmente, as coleções são de altitudes abaixo de $1.500 \mathrm{~m}$, mas, que tem sido citada para a Venezuela em elevações de 3.000 m. No Equador a espécie é bastante rara.

3. Hebanthe occidentallis (R.E.Fr.) Borsch \& Pedersen, Sendtnera 4.21. $1997 . \quad$ Fig. $3 \mathrm{a}-\mathrm{g}$ Pfaffia occidentalis R.E.Fr., Ark. Bot. 16(12): 8. 1920. Tipo: ARGENTINA. PROV. JUJUY: Quinta pr. Laguna de 1 a Brea ad Sierre Sta Bárbara, 8.VII.1901, fl. e fr., R.E. Fries 448 (holótipo S- fotografia !).

Subarbusto escandente, caule com ramos pilosos, pulverulentos, tricomas estrelados articulados; folhas ovadas a ovado-elípticas, 4-9 $\times 1,5-4 \mathrm{~cm}$; pecíolos pilosos, tricomas estrelados, articulados, 0,8-1 cm compr., ápice acuminado, base arredondada, face adaxial glabra a levemente pilosa nas nervuras, tricomas estrelados, articulados, face abaxial breve a densamente pilosa, tricomas estrelados, articulados; inflorescência espiga, em 

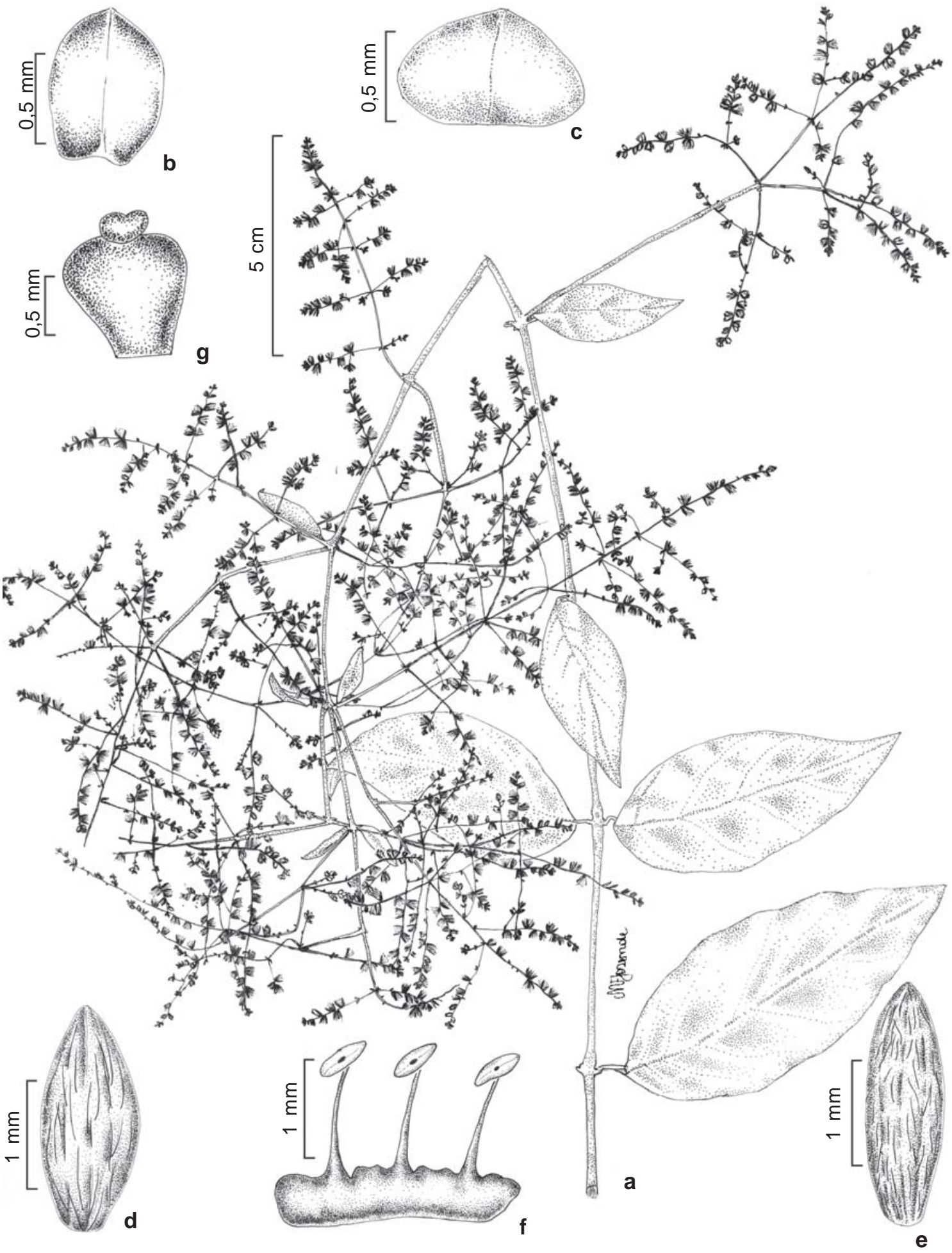

Figura 2 - Hebanthe grandiflora (Hook.) Borsch \& Pedersen - a. hábito; b. bráctea mediana; c. bráctea lateral; d. sépala externa; e. sépala interna; f. tubo estaminal; g. ovário. (Folli 1975, HRCB).

Figure 2 - Hebanthe grandiflora (Hook.) Borsch \& Pedersen - a. habit; b. median bract; c. lateral bract; d. outer sepal; e. inner sepal; f. staminal tube; g. ovary (Folli 1975, HRCB). 
panícula, multicotômica, axilar ou terminal, flores castanho-claras, 3-4 mm compr., pedúnculo piloso, pulverulento, tricomas estrelados, articulados; bráctea mediana orbicular ou ovada, uninervada, pilosa no dorso, 1,2 mm compr., brácteas laterais orbiculares ou ovadas, univervadas, brevemente pilosas no dorso, $1,5 \mathrm{~mm}$ compr.; três sépalas externas ovado-oblongas, pilosas no dorso, ápice agudo, trinervadas, 2,5-3 mm compr., duas sépalas internas mais claras, lanceoladas, pilosas, 2,5-3 mm compr., entre as sépalas externas e internas, grande quantidade de tricomas, alvos, quase do mesmo tamanho das sépalas; tubo estaminal com base dilatada, sem filamentos laterais, filamento anterífero subulado, anteras oblongas, 0,5 mm compr.; ovário obovado, 1 mm compr., estigma capitadoemarginado.

Material examinado selecionado: ACRE: Rio Branco, near mouth of Rio Macauhan, tributary of Rio Yaco, 8.VIII.1933, fl. e fr., B A. Krukoff's 5346 (SP); Zoobotanical garden of the Federal University of Acre, 24.XI.1980. fl. e fr., A. Lowreie et al 139 (CTES, NY). MATO GROSSO: s.l., s.d., fl., L. Smith 238(CTES, R). RORAIMA: Boa Vista, Reserva Ecológica de Maracá, 8.III.1987, fl. e fr., R.M. Harley 24738 (CTES).

Material adicional examinado: ARGENTINA. CHACO, Jujuy, El Carmen, about $10 \mathrm{~km}$ from Perico del Carmen on road to Salta, 3.XI.1984, fl. e fr., T.M. Pedersen 13937(CTES). SALTA:Anta, Parque Nacional El Rey, 24.IX.1985, fl. e fr., A.H. Gentry et al. 51785 (CTES); TUCUNAN: Horco Molle, 8.X.1966, fl. e fr., A.E. Burkart 26529 (SI). BOLIVIA. BENI: Marban, Estación Experimental Najanjito $25 \mathrm{~km}$ of Trindad, 26.VII.1982, fl. e fr., J.C. Solomon et al. 8118 (CTES). PANDO: Manuripi, Antes de Puerto Fátima, Rio Madre de Dios, 3.IX.1985, fl. e fr., J.C. Moraes 443 (CTES). SANTACRUZ: La Paz, Larecaja, $2 \mathrm{~km} \mathrm{~S} \mathrm{de}$ Teopode Diosnte, 2.VIII.2003, fl. e fr., M.S. Ferrucci et al. 2034 (CTES); PANDO: Madre de Dios, Gonzalo Moreno, 18 km SW of Riberalta, 8.IX.1985, M. Nee 31851 (CTES). TARIJA: Arce, Valley of the Rio Chillaguatas, 14.X.1983, fl. e fr., J. C. Solomon 11260 (CTES). PARAGUAI. AMAMBAY: San Pedro, Línea Ovetense, 3.X.1987, fl., E.M. Zardini \& B. Benitez 3366 (CTES). PERU. CUZCO: Madre de Dios, Tambopata, 23.VII.1989, fl. e fr., R.C.Alexadre \& R. Byrne 874 (CTES).

Distribuição geográfica e hábitat: no Brasil, somente nos estados do Acre, Mato Grosso e
Roraima, em beira de rios e orla de matas, em altitudes de 66 a 153 m. Também ocorre na Argentina, Bolívia, Paraguai e Peru.

Fries (1920) considerou a espécie pertencente ao gênero Pfaffia e comentou que $P$. occidentalis pode ser separada de $P$. paniculata pela morfologia completamente diferente do androceu, sem filamentos no tubo. Stützer (1935) seguiu o mesmo conceito de Fries (l. $c$.) excluindo a citação do tipo da mesma. Borsch \& Pedersen (1997) fizeram uma nova combinação, considerando Pfaffia occidentalis R.E. Fr. como Hebanthe occidentalis. Esta espécie diferencia-se das demais principalmente pelo tipo de tricomas estrelados e também pelo tubo estaminal sem os filamentos laterais. Hebanthe occidentalis tem pouca reprentatividade no Brasil por ocorrer principalmente na Região Norte, onde as dificuldades para coleta são maiores em decorrência da distância e recursos fianceiros.

4. Hebanthe pulverulenta Mart., Beitr. Amarantac. 97. 1825. Tipo: BRASIL. SÃO PAULO, in marginibus sylvarum ad Ypanema, F. Sellow $s / n$. (Holótipo M). $\quad$ Fig. 4 a-f

Pfaffia pulverulenta (Mart.) Kuntze f. densepilosa Suess., Repert. Spec. Nov. Regni Veg. 35: 333. 1934. Tipo:BRASIL: F. Sellow $s / n$ (herbário não mencionado). Syn nov.

Pfaffia pulverulenta (Mart.) Kuntze f. glabriuscula Suess., Repert. Spec. Nov. Regni Veg. 35: 333. 1934. Tipo: BRASIL. Blumenau, E. Ule 857. RIO DE JANEIRO: Theresopolis, I. T. de Moura 982 (Sintipos W). Syn nov.

Pfaffia pulverulenta (Mart.) Kuntze var. microdonta Stützer, Repert. Spec. Nov. Regni Veg. 88: 18. 1935. Tipo: BRASIL. ACRE: Seringal S.Francisco, VIII.1911, E. Ule 9356 e 9357 (Sintipos K). Syn nov.

Pfaffia pulverulenta (Mart.) Kuntze var. macrodonta Stützer, Repert. Spec. Nov. Regni Veg. 88: 18. 1935. Tipo: BRASIL. SANTA CATARINA: M. Fox 183 (K- fotografia !); J. Lhotzky 108 (W). SÃO PAULO: Barra Mansa, VI.1901, F. F. Wettstein \& V. F Schiffner. s/n (Sintipos W). Syn nov.

Subarbusto, escandente ou semi-escandente, $1 \mathrm{~m}$ de altura, caule com ramos estriados, glabros, 


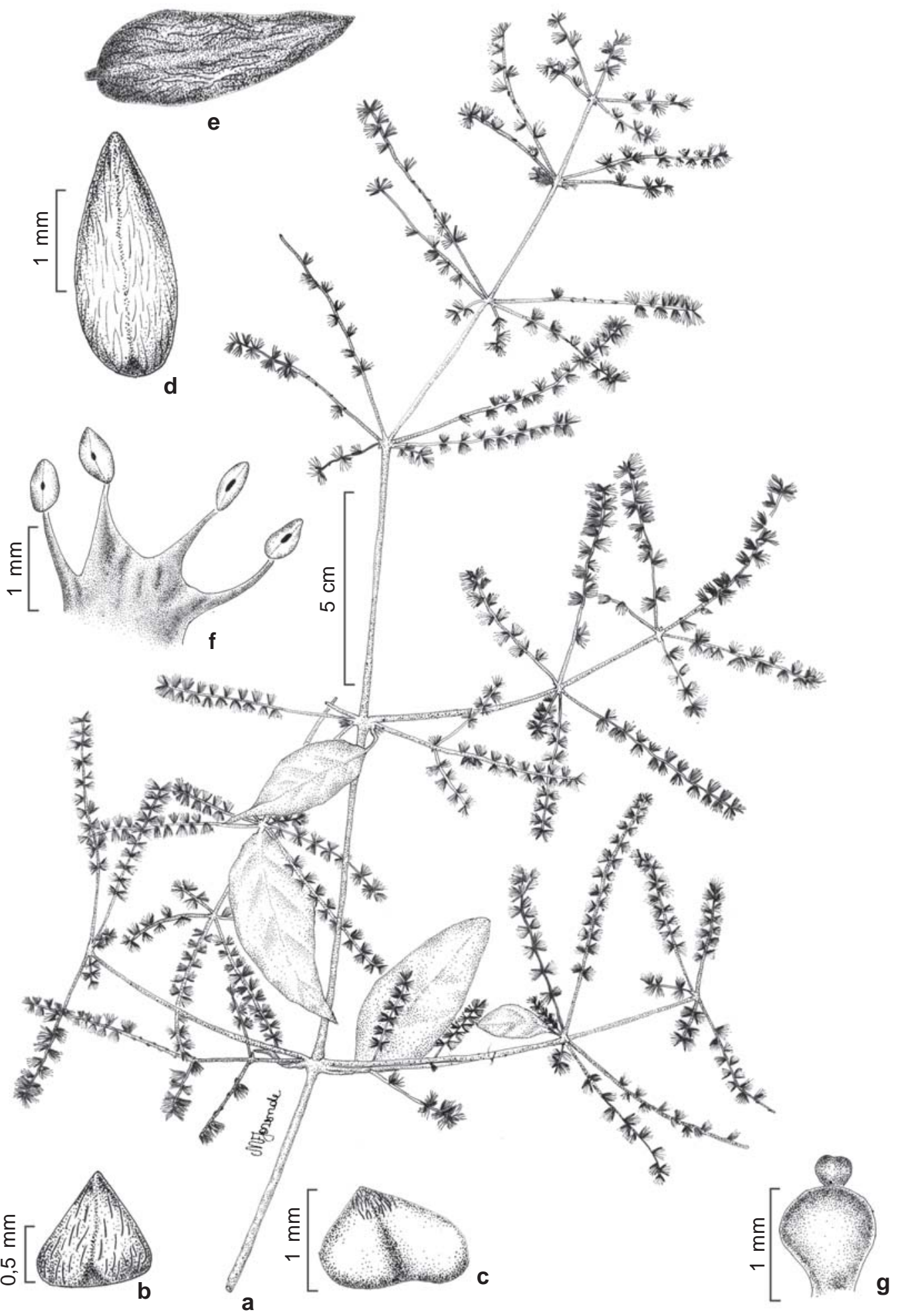

Figura 3 - Hebanthe occidentallis (R. E. Fr.) Borsch \& Pedersen - a. ramo; b. bráctea mediana; c. bráctea lateral; d. sépala externa; e. sépala interna; f. tubo estaminal; g. ovário. (Smith $s / n, \mathrm{R})$.

Figure 3 - Hebanthe occidentallis (R. E. Fr.) Borsch \& Pedersen - a. branch; b. median bract; c. lateral bract; d. outer sepal; e. inner sepal; f. staminal tube; g. ovary. (Smith $s / n, \mathrm{R})$. 
semiglabros a pilosos nos ramos mais jovens, tricomas estrelados, pulverulentos; folhas elípticas, ovadas ou ovado-elípticas, 3,8-12,2× 1,7-6 cm, pecíolo densamente piloso, tricomas estrelados, pulverulentos, 0,1-1,5 cm compr., ápice agudo a acuminado, base aguda, atenuada a obtusa, face adaxial esparsamente pilosa, tricomas estrelados, face abaxial pilosa, mais densamente sobre as nervuras, tricomas estrelados, pulverulentos; inflorescência espiga, em panícula, multicotômica, axilar ou terminal, flores pequenas, brancas ou esverdeadas, 2-2,5 $\mathrm{mm}$ compr., pedúnculo piloso, tricomas estrelados, densamente pulverulentos; bráctea mediana orbicular ou suborbicular, uninervada, escariosa, translúcida, pilosa, 0,8-1,2 mm compr., brácteas laterais orbiculares, uninervadas, nervura castanhoescura, proeminente, escariosas, translúcidas, 11,5 mm compr.; três sépalas externas, ovadoelípticas, 1-3 nervuras, castanho-escuras, 2-3 mm compr., sépalas internas elípticas a ovado-elípticas, 1-2 nervuras, castanho-claras, 2-2,5 mm compr., grande quantidade de tricomas setosos entre as sépalas externas e internas; tubo estaminal com filamentos laterais de base dilatada, triangulares, curtos, filamento central anterífero linear, longo, anteras elípticas a oblongas, $0,5-0,6 \mathrm{~mm}$ compr.; ovário ovado, 0,8-1,5 mm compr., estigma capitado. Material examinado selecionado: ESPÍRITO SANTO: Vitória, estrada entre Manhaçú e Vitória, km 89, 7.IX.1977, fl. e fr., J.D. Shepherd et al. 5836 (R). MATO GROSSO: Cuiabá, Serra Ricardo Franco, VIII.1978, fl., Marioni 107 (SJRP). MINAS GERAIS: Araponga, Serra da Grama, estrada para Bom Jesus da Madeira, 7.X.1986, fl. e fr., J. Vieira et al. 450 (VIC). Lima Duarte, Serra da Ibitipoca, 17.IX.1940, fl. e fr., $M$. Magalhães 463 (BHCB). São João Del Rei, Serra do Lenheiro, X.1896, fl., M.S. Silveira 1712(R). Vale Verde, Parque Nacional da Serra do Caparaó, 27.IX.1977, fl. e fr., L. Krieger et al. 1258 (VIC). PARANÁ: Antonina, Rio Cotia, 2.VI.1989, fl. e fr., G. Hatschbach et al. 53114 (CTES). Campina Grande do Sul, Morro Guaricana, 7.II.1968, fl. e fr., G. Htaschbach et al 18546 (CTES). Engenheiro Passos, 8.X.1982, fl. e fr., G. Hatschbach \& R. Kummrow 45534 (CTES). Morretes, Estrada da Graciosa, GrotaFunda, 26.V.1976, fl. e fr., G Hatschbach 41542 (CTES, NY, UB). Paranaguá, Pico Torto, 11.XI.1969, fl., G. Hatschbach 22874 (CTES). Quatro Barras, Serra da Baitaca, 4.VI.1996, fl., C. Gatti et al. 47 (BHCB). Säo José dos Pinhais, Guaricana, 23.V.1978, fl. e fr., G Hatschbach 41546(CTES). RIODEJANEIRO: Itatiaia, Parque Nacional, 14.VII.1967, fl. e fr., J. Mattos \& N.F. Mattos 14679 (SP). Nova Friburgo, Reserva Municipal de Macaé de Cima, 17.VII.1989, M. Peron et al. 797 (GUA, NY). Teresópolis, Parque Nacional da Serra dos Órgãos, 4.VIII.1963, fl. e fr., G.F.J. Pabst 7370 (CTES, NY). SANTACATARINA: Blumenau, Morro Spitzkopf, 5.VII.1960, fl. e fr., R. Reitz \& R. Klein 9695 (HBR, NY). Joinvile, Estrada DonaFrancisca, 26.V.1957, fl. e fr., R. Reitz \& R. Klein 4246 (B, HBR, NY, PACA). Papanduva, Serra do Espigão, 20.IV.1962, fl. e fr., $R$. Reitz \& R. Klein 12683 (HBR, NY). Rancho Queimado, 14.IV.1982, fl. efr., J. Mattos 23303 (HAS); SäoFrancisco do Sul, Garuva, Porto Palmital, 25.V.1957, R. Reitz \& R. Klein 4214 (HBR, PACA). Vidal Ramos, Sabiá, 14.VII.1957, fl. e fr., R. Reitz \& R. Klein 4283 (HBR, PACA). SÃOPAULO: Biribiba Ussu, SP98, póximo o rio Guacá, 25.VII.1993, fl. e fr., J.R. Pirani et al 736 (SP, SPF). Guaratinguetá, Entre Itajubáe Guaratinguetá, Serra da Mantiquera, 14.VII.1962, fl. e fr., A. Castellanos 23383 (GUA, HRB, NY). Jacupiranga, 30.V.1966, fl., J. Mattos 13700 (GUA); Paranapiacaba, 18.VIII.1990, fl. e fr., $A$. Freire-Fiero 1631 (SPF).

Distribuição geográfica e hábitat: Brasil, nas Regiões Sul, Sudeste e Centro-Oeste, em floresta pluvial atlântica, em ambientes de clareiras e orlas de matas e borda de rios, com altitudes que variam de $200-1.300 \mathrm{~m}$.

Fries (1920) considerou Pfaffia pulverulenta pertencente ao gênero Pfaffia e comentou que a mesma, até a data do seu trabalho, somente era conhecida para os estados do Rio de Janeiro e de São Paulo. O autor (l. c.) ao analisar o material do Paraná, colocou em dúvida se realmente este material pertencia à Pfaffia pulverulenta porque, segundo a descrição de Seubert (1875), não coincidia com a descrição original de Martius (1825). Este autor (l. c.) designava os tricomas, encontrados nos ramos e folhas, como estrelados, ao passo que Seubert $(l . c$.) denominava-os de ramoso-verticilados.

Seubert (1875) descreveu uma nova variedade, Pfaffia pulverulenta var. rufescens Seub. baseando-se na característica de ramos inferiores cobertos de um tomento rufo-ferrugíneo. Sussenguth (1934) teceu comentários a respeito da interpretação dos tricomas dada por Martius (1825)e Seubert (1875) e discutida por Fries (1920), argumentando que na realidade não existem contradições, somente são maneiras diferentes 


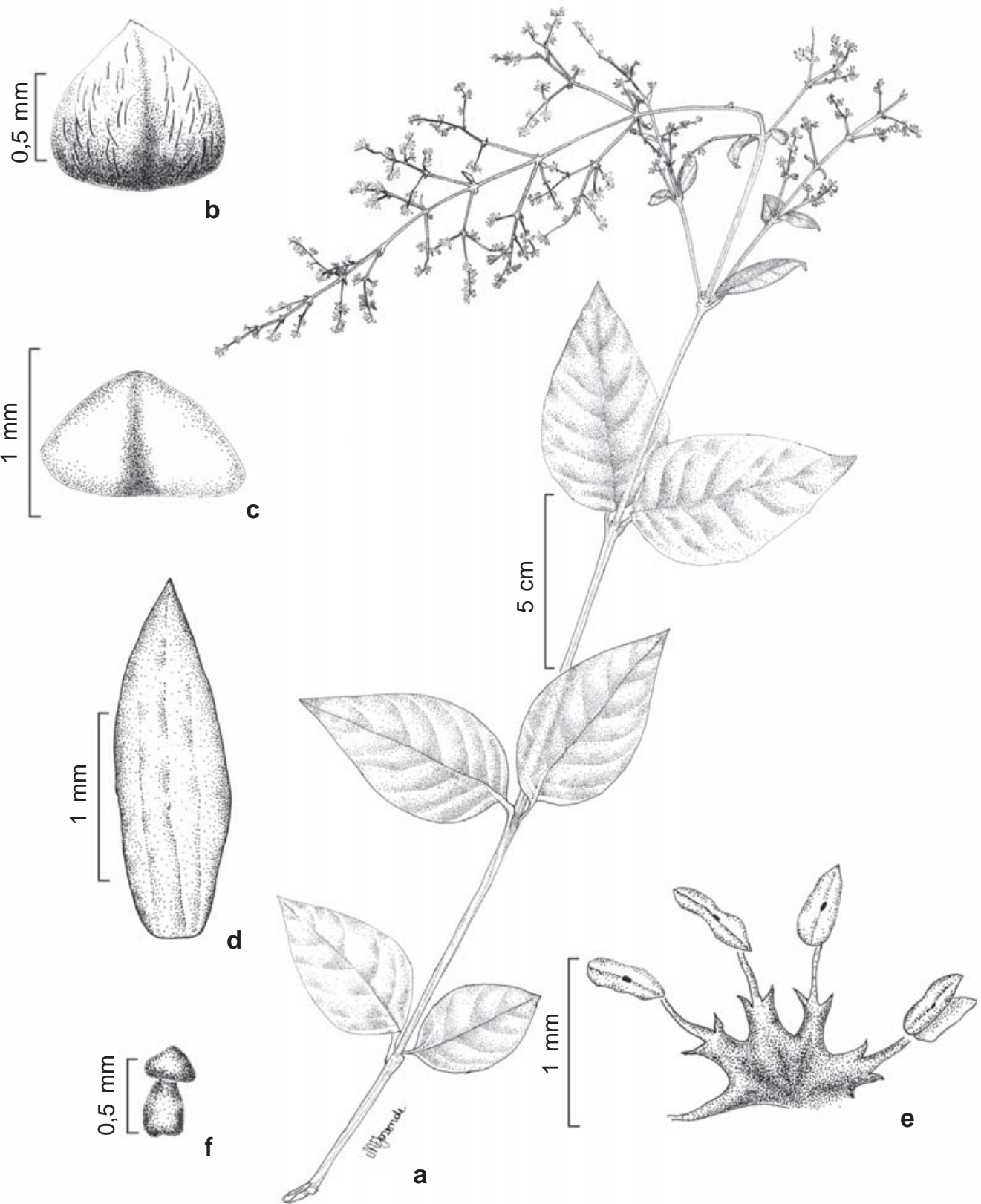

Figura 4 - Hebanthe pulverulenta Mart. - a. ramo; b. bráctea mediana; c. bráctea lateral; d. sépala; e. tubo estaminal; f. ovário. (Dusén $s / n, \mathrm{NY}$ ).

Figure 4 - Hebanthe pulverulenta Mart - a. branch; b. median bract; c. lateral bract; d. sepal; e. estaminal tube; f. ovary. (Dusén $s / n, \mathrm{NY}$ ).

para descrever esta característica e que o material coletado por Dusén no Paraná, pertencia realmente à $P$. pulverulenta.

Sussenguth (1934) descreveu três novas formas para Pfaffia pulverulenta: $\mathrm{f}$. densepilosa, f. mostruosa eriantha e f. glabriuscula com base na face abaxial da folha que apresentava tricomas verticilados densos ou laxos e dispersos.

Stützer (1935) seguiu a mesma interpretação de Seubert $(l . c$.) quanto à designação dos tricomas e apresentou três variedades para Pfaffia pulverulenta, sendo duas novas para a ciência: variedade microdonta, com folhas de face 
adaxial glabra e a abaxial provida de tricomas verticilados, laxos, semelhantes à forma típica e filamentos laterais muito pequenos, arredondados, obtusos. Já a variedade macrodonta, de acordo com a autora ( $l$. c c.), é híbrida entre Pfaffia paniculata e $P$. pulverulenta.

Borsch \& Pedersen (1997) comentaram que das três formas descritas por Suessenguth (1934), f. densepilosa, f. grabriuscula e f. monstr. eriantha, as duas primeiras poderiam tornar-se sinônimos de $P$. pulverulenta, a terceira os autores já consideravam sinônimo, pois diferia somente pelas flores deformadas. Borsch $\&$ Pedersen (l. c.) ainda argumentaram que Stützer (1935) distinguiu duas variedades, var. microdonta e var. macrodonta com base em diferenças nos tamanhos dos filamentos do tubo estaminal e que seu valor taxonômico somente poderia ser avaliado após uma revisão crítica, incluindo uma análise estatística quantitativa dos dados. Os autores ( $l$. c . ) não apresentarm nenhuma lista de material examinado.

No presente trabalho propõe-se a sinonimização de Pfaffia pulverulenta (Mart.) Kuntze f. densepilosa Suess., P. pulverulenta (Mart.) Kuntze f. glabriuscula Suess., $P$. pulverulenta (Mart.) Kuntze var. microdonta Stützer e $P$. pulverulenta (Mart.) Kuntze var. macrodonta Stützer em favor de Hebanthe pulverulenta Mart. Os exemplares-tipo destas formas e/ou variedades não foram examinados, pois para alguns não há menção dos herbários em que estão depositados, enquanto outros não foram disponibilizados pelos respectivos herbários. Estas formas e/ou varidades foram estabelecidas a partir da análise de material herborizado sem uma visão da plasticidade do grupo, cujas variações morfológicas são condicionadas pelo ambiente de ocorrência. Pelas descrições originais e materiais examinados não existem subsídios de valor taxonômico fortes para mantê-las válidas.

5. Hebanthe reticulata (Seub.) Borsch \& Pedersen, Sendtnera 4: 20. $1997 . \quad$ Fig. 5 a-f Gomphrena reticulata Seub., in Mart., Fl. bras. 5(1): 194. 1875. Tipo: BRASIL. MINAS GERAIS: Ad Chapada et Rio Jequitinhonha,
J.B.E. Pohl 3255 (W, perdido). BRASIL. MINAS GERAIS, J.B.E. Pohl3255 (lectótipo M- fotografia NY!, designado por T. M. Pedersen (2000)). Pfaffia reticulata (Seub.) Kuntze f. obtusiuscula Suess. Repert. Spec. Nov. Regni Veg. 35:333.1934. Tipo: BRASIL. RIO DE JANEIRO: A.F.M. Glaziou 13116 (B!). Syn nov.

Subarbusto ou arbusto, escandente, 0,90$2 \mathrm{~m}$ de altura, caule ramoso, lenhoso na base, ascendente, escuro, glabro; folhas ovadas ou ovado-oblongas, 2-7,5 × 1-3,7 cm, pecíolos curtos, glabros, $0,5 \mathrm{~cm}$ compr., ápice acuminado, base aguda, face adaxial glabra, face abaxial glabra a brevemente estrigosa a pilosa, tricomas rufos, principalmente nas nervuras, nervuras secundárias formando um reticulado; inflorescência espiga em panícula, multicotômica, axilar ou terminal, flores pequenas, esbranquiçadas, 2 $3 \mathrm{~mm}$ compr., pedúnculo glabro, bráctea mediana suborbicular, persistente, uninervada, pilosa na base, $1 \mathrm{~mm}$ compr., brácteas laterais orbiculares, uninervadas, um tufo de tricomas na base, rufos, 1,5 mm compr.; três sépalas externas, ovadas, ápice agudo, trinervadas, pilosas, rufescentes, 2-2,5mm compr., duas sépalas internas, ovadas, claras, trinervadas, 2-2,5 mm compr., grande quantidade de tricomas entre as sépalas externas e internas; tubo estaminal curto, filamentos laterais subulados a filiformes quase do mesmo tamanho do anterífero subulado, anteras elípticas, 0,5-0,7 mm compr.; ovário obovado a oblongo, $1 \mathrm{~mm}$ compr., estigma capitado, bilobado.

Material examinado selecionado: BAHIA: Abaíra, estrada Abáira-Piatã, brejo, 28.X.1992, fl. e fr., W. Ganev 1393 (CTES). Caetité, 3 km de Caetité en la ruta de Caetité a Brumado, 12.VIII.1996, fl. e fr., M.S. Ferrucci et al. 1027 (CTES). Maracás, ca. 20 km W de Marcas, na estrada para Contendas do Sincorá, 1.VII.1993, fl. e fr., L.P. Queiroz et al. 3279 (NY). Rod. BR-4, $12 \mathrm{~km} \mathrm{~N}$ da divisa Minas-Bahia, 24.VI.1965, fl. e fr., R.P. Belém 1182 (CEPEC, NY, UB). MINAS GERAIS: Itinga, Rod. BR 116, fl. e fr., 15.VII.1982, G. Hatschbach \& O. Guimarães 45021 (CTES, MBM, NY). Medina, 35 km, 9.VII.1964, L. Duarte \& A. Castellanos 278 (CTES, MBM, NY). Tremendal, km 79 da BA, 262 trecho Anaje/Aracatu, 18.VII.1991, fl. e fr., S.C. Sant'Ana et al. 06 (CEPEC, MBM, NY). RIO DE JANEIRO:A.F.M. Glaziou 13116 (B). 


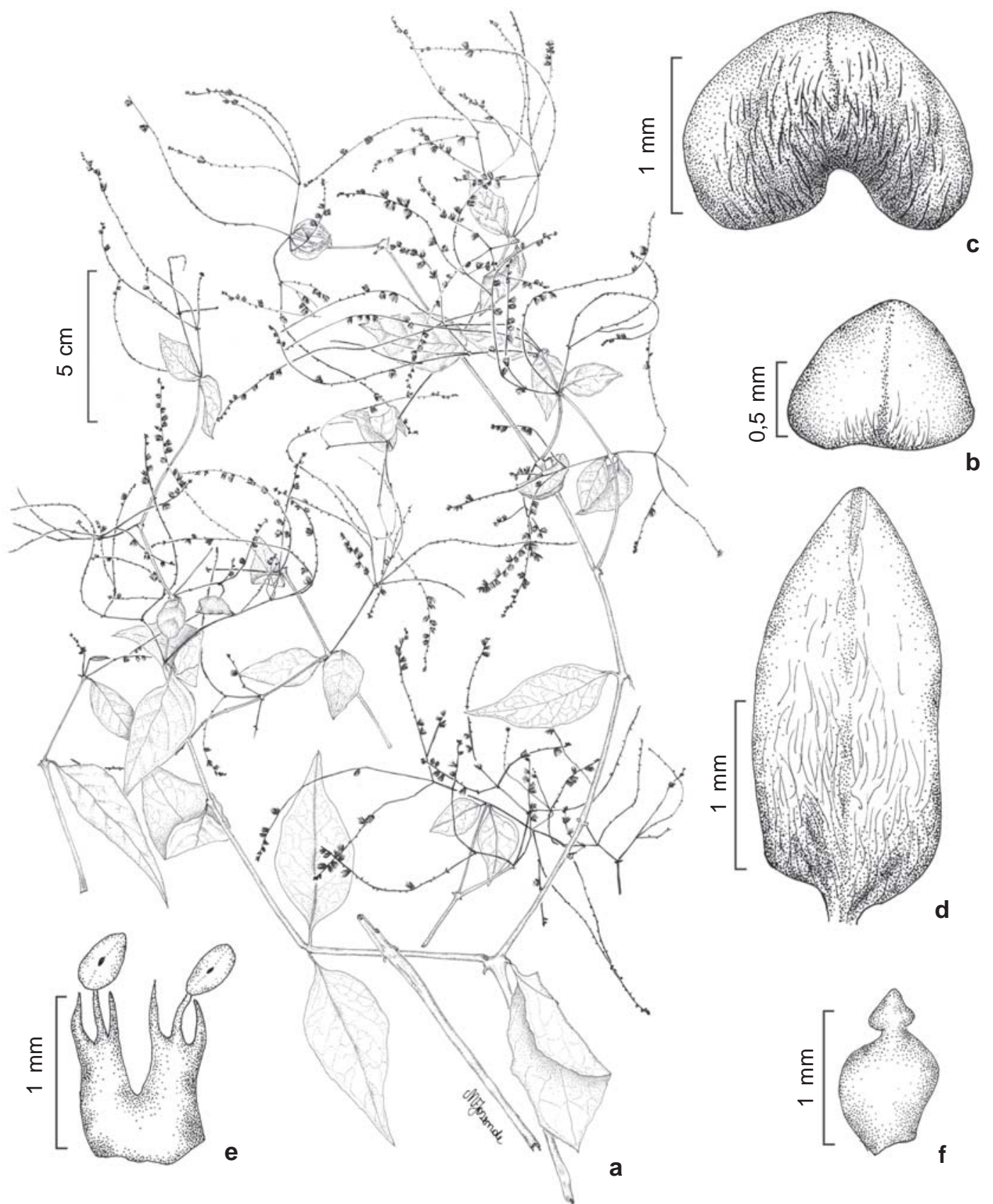

Figura 5 - Hebanthe reticulata (Seub) Borsch \& Pedersen - a. ramo; b. bráctea mediana; c. bráctea lateral; d. sépala; e. tubo estaminal; f. ovário. (Duarte 278, CTES).

Figure 5 - Hebanthe reticulata (Seub) Borsch \& Pedersen - a. branch; b. median bract; c. lateral bract; d. sepal; e. estaminal tube; f. ovary. (Duarte 278, CTES).

Distribuição geográfica e hábitat: Bahia, Minas Gerais e Rio de Janeiro, em caatingas e cerrados.

Suessenguth (1934) descreveu Pfaffia reticulata var. strigulosa destacando o indumento estrigoso na face abaxial da folha e as nervuras não reticuladas, conspícuas. Já, para a forma obtusiuscula Suessenguth (l. c.) salientou que a folha apresentava oápice obtuso, quase aredondado. Stützer (1935) apresentou descrição da espécie e manteve a variedade e a forma criadas por Suessenguth $(l . c)$ mencionando as mesmas características. 
Pedersen (2000) sinonimizou Pfaffia reticulata (Seub.) Kuntze var. strigulosa Suess., em favor de Hebanthe eriantha (Poir.) Pedersen, sem tecer qualquer comentário. Acredita-se que o posionamento de Pedersen (l. c) se deva a fato de que as características apontadas por Sussenguth $(l . c$. $)$, para esta variedade, foram folhas com indumento estrigoso na face abaxial nervuras reticuladas, conspícuas; características estas pertinentes mais a $H$. eriantha do que a $H$. reticulata, o qual concorda-se plenamente.

No presente trabalho, propõe-se a sinonimização de Pfaffia reticulata (Seub.) Kuntze f. obtusiuscula Suess. em favor de Hebanthe reticulata (Seub.) Borsch \& Pedersen. Entre o material examinado, não se encontrou nenhum exemplar com as características apresentadas por Suessenguth (1934) para criar a forma obtusiuscula. Ao examinar-se o material-tipo constatou-se que a forma do ápice é acuminada, não obtusa como designado por Suessenguth (l.c.). Associado a isso, na exsicata do material-tipo encontrou-se uma etiqueta, com data 1998, assinada por T. Mendel Pedersen identificando este material como Hebanthe reticulata (Seub.) Borsch \& Pedersen.

6. Hebanthe spicata Mart., Beitr. Amaranthac.: 97. 1825. Tipo: BRASIL. MINAS GERAIS: in mediterraneis deserti versus fluvium $S$. Francisci, C. F. P. Martius $s / n$ (Holótipo M). Fig. 6 a-g Pfaffia spicata (Mart.) Kuntze var. pretensis Suess., Repert. Spec. Nov. Regni Veg. 35: 333. 1934. Tipo: BRASIL. MINAS GERAIS: Preto, locis umbrosis ad rivulos, W. Schwacke 11692 e 1169, Mariana, W. Schwacke 8953 (Sintipos B). Syn nov.

Arbusto, ereto ou escandente, 1,5-2 m de altura, caule estriado, glabro, piloso a velutino, principalmente nos ramos jovens, tricomas adpressos, articulados, ferrugíneos; folhas ovadas, ovado-elípticas, 4-6,5 $\times 1,5-3 \mathrm{~cm}$; pecíolo curto, velutino, ferrugíneo, $0,5 \mathrm{~cm}$ compr.; ápice agudo a acuminado; base aguda a arredondada; face adaxial esparsamente híspida a pilosa, tricomas adpressos, articulados, face abaxial híspida, pilosa a velutina; inflorescência espiga, em panícula, tricotômica, axilar ou terminal, flores pequenas, esbranquiçadas a castanhas $2-3 \mathrm{~mm}$ compr., pedúnculo densamente velutino, ferrugíneo; bráctea mediana subglobosa, côncava, uninervada, pilosa, castanho-clara, $1 \mathrm{~mm}$ compr., brácteas laterais subglobosas, uninervadas, nervura castanho-escura, pilosas no dorso, castanhoclaras, 1,2-1,5 mm compr.; três sépalas externas, ovadas a ovado-lanceoladas, ápice agudo, trinervadas, nervuras escuras, pilosas no dorso, castanho-escuras a castanho-claras, 2-3 mm compr., duas sépalas internas ovadas a ovadolanceoladas, trinervadas, pilosas no dorso, mais claras que as externas, 2-3 mm compr., grande quantidade de tricomas longos entre as sépalas externas e internas; tubo estaminal curto, filamentos laterais falcados, maiores que o tamanho do filamento anterífero ou do mesmo tamanho, filamento anterífero linear, anteras oblongas, 0,5 mm compr.; ovário globoso a ovado, 0,7-1 mm compr., estigma capitadobilobado.

Material examinado selecionado: MINAS GERAIS: Araçuaí, em área de contato estepe/floresta estacional, 6.VII.1981, fl. e fr., S.J. Filho 145 (HRB, IBGE). PARANÁ: Ponta Grossa, Passo do Pupo, na orla do mato, 8.IX.1967, fl. e fr., $G$. Hatschbach 17142 (MBM) SÃO PAULO: Campinas, Av. Brasil, 30.VI.1936, fl. e fr., A.M. Carvalho 654 (ESA).

Distribuição geográfica e hábitat: no Brasil nos estados de Minas Gerais, Paraná e São Paulo, em orla de matas, em altitudes a partir de $200 \mathrm{~m}$.

Suessenguth (1934) descreveu Pfaffia spicata var. pretensis com base nos tricomas da face abaxial da folha e filamentos laterais do tubo estaminal. Stützer (1935) também citou a var. pretensis seguindo a mesma interpretação de Suessenguth $(l . c)$. Borsch \& Pedersen (1997), ao reestabelecerem o gênero Hebanthe, comentaram que a variedade pretensis, proposta por Suessenguth(1934), difere da variedade típica na morfologia dos tricomas e do androceu, e que é muito duvidoso separalá, porém, para uma melhor apreciação, seria necessária uma revisão crítica. Os autores não apresentaram nenhuma lista de material examinado e somente fizeram considerações. 

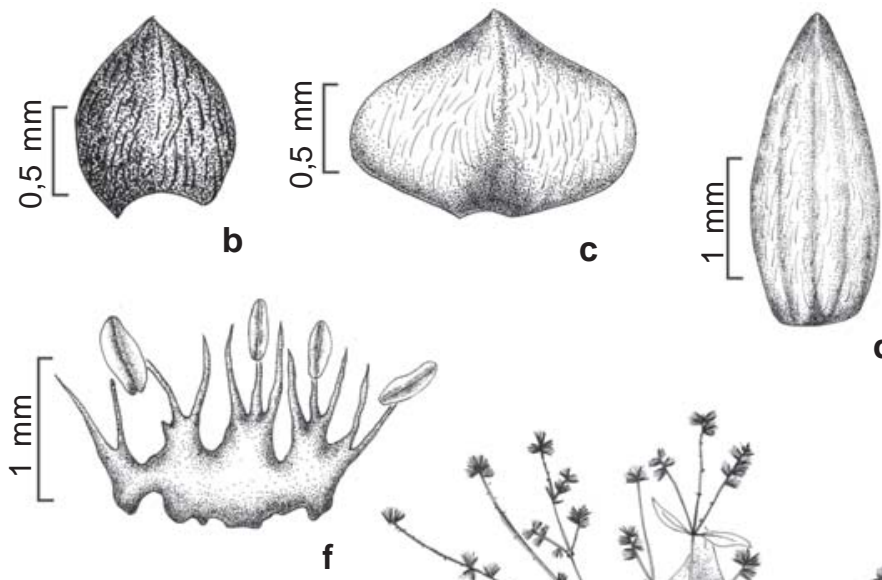

C

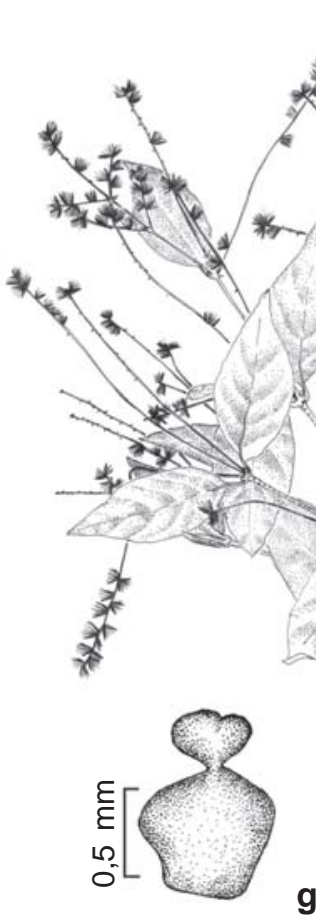

g
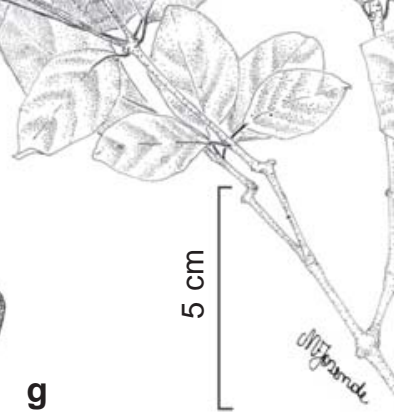

d
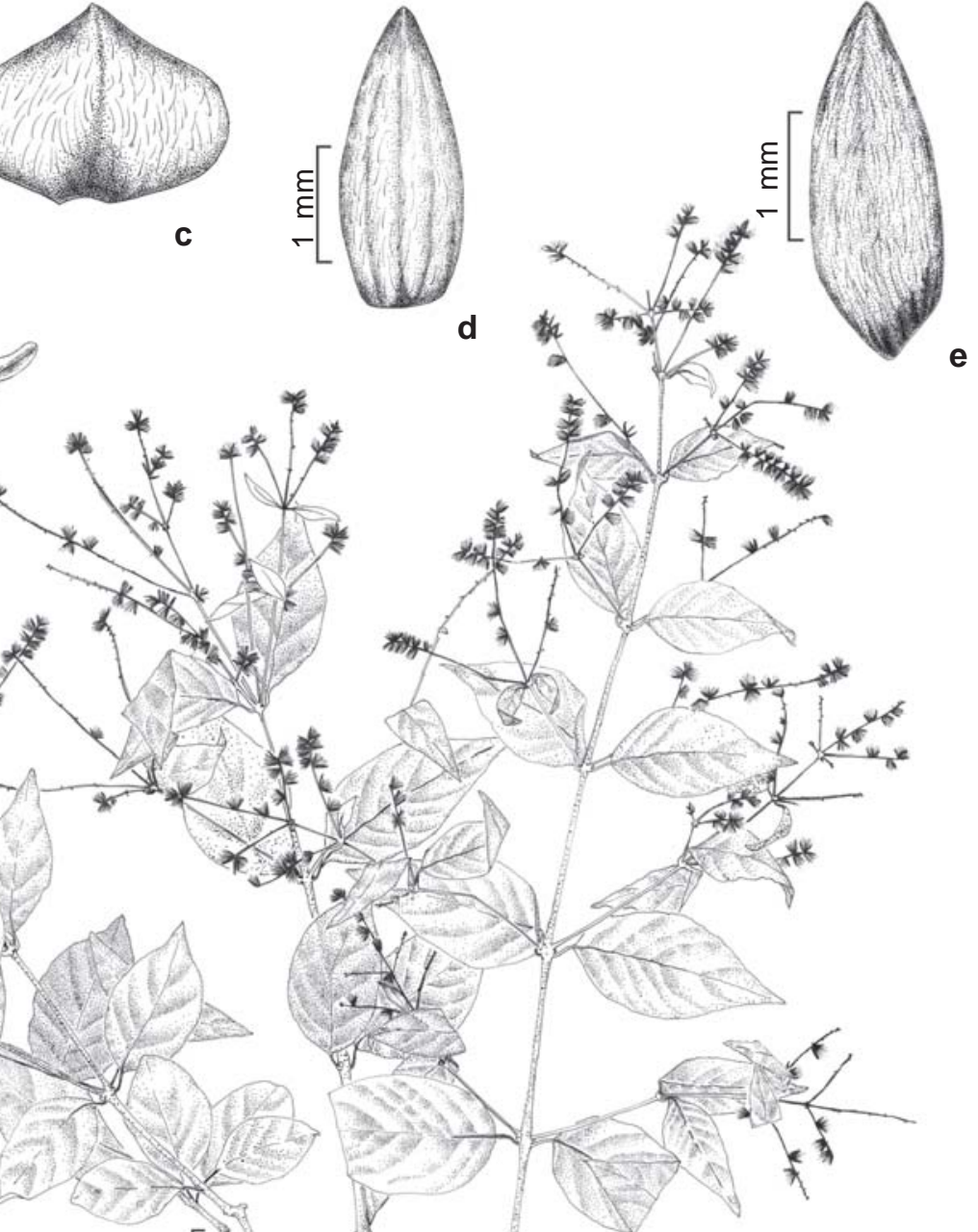

Figura 6-Hebanthe spicata Mart. - a. ramo; b. bráctea mediana; c. bráctea lateral; d. sépala externa; e. sépala interna; f. tubo estaminal; g. ovário. (Salim J. Filho 145, HRB).

Figure 6 - Hebanthe spicata Mart. - a. branch; b. median bract; c. lateral bract; d. outer sepal; e. inner sepal; f. staminal tube; g. ovary. (Salim J. Filho 145, HRB).

Neste trabalho propõe-se a sinonimização de Pfaffia spicata (Mart.) Kuntze var. pretensis Suess. em favor de Hebanthe spicata Mart. Embora tenham sido examinados poucos espécimes, as características morfológicas apresentadas na descrição da variedade não se mostraram consistentes nem descontínuas, não justificando a manutenção desta variedade.

\section{REFERÊNCIAS BIBLIOGRÁFICAS}

Andrade-Lima, D. 1981. The caatingas dominium. Revista Brasileira de Botânica 4(2): 149-153.

APG II. The Angiosperm Phylogeny Group 2003. An update of Angiosperm Phylogeny Group classification for the orders and families of flowering plants: APG II. Botanical Journal of the Linnean Society 141:399-436. 
Borsch, T. \& Pedersen, T. M. 1997. Restoring the generic rank of Hebanthe Martius (Amaranthaceae). Sendtnera 4: 13-31.

Brummit, R. K \& Powell, C. E. 1992. Authors of plant names. Royal Botanic Gardens, Kew. 732p.

Cabrera, A. L. \& Willink, A. 1980. Biogeografia de America Latina. 2 ed. OEA, Washington. 117p.

Dietrich, D. 1839. Synopsis Plantarum. v.1. Weimar. $546 \mathrm{p}$.

Eiten, G. 1990. A vegetação do cerrado. In: Pinto, M. N. (org.) Cerrado: caracterização, ocupação e perspectivas. Ed. UNB, Brasília. Pp. 09-65.

Eliasson, U. H. 1987. Amaranthaceae. In: Harling, G. \& Anderson, L. (eds.). Flora of Ecuador Gothenburg, Department of Systematic Botany. University of Gothenburg and Stockholm the section for Botany. Museum of Natural History. n.28. Pp. 52-60.

Endlicher, S. 1837. Amaranthaceae. Genera Plantarum Secundum Ordines Naturales. Wien, Fr. Beck. 4: 300-304.

Fernandes, A. 1998. Fitogeografia brasileira. Fortaleza, Multigraf Editora Ltda. 340p.

Fries, R.E. 1920. Revision der von Glaziou in Brasilien Gesammelten Amaranthaceen. Arkiv För Botanik 16(13): 1-21.

Heimerl, A. 1908. Amaranthaceae. In: Wettstein, R. v. \& Schiffner, V. Ergebnisse der Botanischen Expedition der Kaiserlichen Akademic der Wissenschaften nach Südbrasilien. 1901. v.1. Pteridophyta und Anthophyta. Denkschriften der Kaiserlichen Akademie Wissenchaften. Wien, Mathematisch, Naturwissenschaftliche. Klasse. Pp 230.

Hickey, L. J. 1974. Classificatión de la arquitetura de las hojas de dicotiledôneas. Boletin de la Sociedad Argentina de Botánica. 16(1-2):1-25.

Hooker, W.J. 1837. Ícones Plantarum 2 London. $102 p$.

Judd, W. S.; Campbell, C. S.; Kellogg, E. A.; Stevens, P. F. \& Donoghue, M. J. 2002. Plant systematics. A phylogenetic approach. 2 ed. Sinauer Associates, Sunderland. 576p.

Kuntze, O. 1891. Revisio generum plantarum. Pars. II. Leipzig. Pp 543-544.
Lawrance, G. H. M.; Buchheim, A. F. G.; Daniels, G. S \& Dolezal, H. 1968. Botanico-PeriodicumHuntianum. Pittsburg, Hunt Botanical Library. $1063 p$.

Marchioretto, M. S.; Miotto, S. T. S. \& Siqueira, J. C. 2008. Padrões de distribuição geográfica dos táxons brasileiros de Hebanthe Mart. (Amaranthaceae). Pesquisas Botânica 59: 159-170.

Martius, C. F. P. v. 1825. Beitrag zur Kenntnis der natürlichen familie der Amaranthaceen. Bonn. 321p.

Martius, C. F. P. v. 1826. Nova genera et species plantarum.2 Typis C. Wolf, Monachii. Pp. 1-64.

Payne, W. W. 1978. A glossary of plant hair terminology. Brittonia 30(2): 239-255.

Pedersen, T. M. 2000. Studies in South American Amaranthaceae V. Bonplandia 10(1-4): 83-112.

Radford, A.E.; Dickson, W.C.; Massey, J.R. \& Bell, C.R. 1974. Vascular Plant Systematics. New York, Harper \& Row. 891p.

Rizzini, C.T.; Coimbra Filho, A.F. \& Houaiss, A. 1988. Ecossistemas. Index Ed., Rio de Janeiro. 200p.

Seubert, M. 1875. Amaranthaceae. In: Martius, C. F. P. von; Endlicher, S. \& Urban, I. (eds). Flora brasiliensis. Vol.5. Part.1. Typografia Regia, Monachii. Pp. 188-202.

Stafleu, F. A. \& Cowan, R. S. 1976-1988. Taxonomic literature. Utrech, Bohn, Scheltema \& Holkema. V.1-7 e suplemento.

Stuitzer, O. 1935. Die Gattung Pfaffia mit einemAnhag neur Arten von Alternanthera. Feddes Repertorium Specierum Novarum Regni Vegetabilis 88: 1-49.

Suessenguth, K. 1934. Neue und kritische Amarathaceen aus Süd und Mittelamerika. Feddes Repertorium Specierum Novarum Regni Vegetabilis 35: 298-337.

Thiers, B. 2009. [continuously updated]. Index Herbariorum: A global directory of public herbaria and associated staff. New York Botanical Garden's Virtual Herbarium. http:// sweetgum.nybg.org/ih/. Acesso em 12/2008.

Vasconcellos, J. M. O. 1986. Amaranthaceae do Rio Grande do Sul, Brasil. - V. Gêneros Pfaffia Mart. e Gomphrena Mart. Roessléria 8(2): 75-127. 